\title{
Ensino e Pesquisa na Estratégia de Saúde da Família: o PET-Saúde da FMB/Unesp
}

\author{
Teaching and Research in the Family Health \\ Strategy: the Educational Program for Health \\ Work at the Botucatu School of Medicine/Unesp
}

\author{
Eliana Goldfarb Cyrino \\ Antonio de Pádua Pithon Cyrino ${ }^{I}$ \\ Alice Yamashita Prearo \\ Regina Célia Popim \\ Janete Pessuto Simonetti \\ Paulo José Fortes Villas Boas ${ }^{I}$ \\ Miriam Hashimoto ${ }^{I}$ \\ Karina Pavão Patrício \\ Renata Maria Zanardo Romanholi \\ Cássia Marisa Manoel \\ Paula de Oliveira Montandon Hokama
}

\section{PALAVRAS-CHAVE \\ - Educação Médica \\ - Educação em Enfermagem \\ - Atenção Primária à Saúde \\ - Saúde da Família \\ - Educação em Saúde \\ - Educação Continuada \\ - Programa de Educação pelo Trabalho}

\section{KEYWORDS}

- Medical Education

- Nursing Education

- Primary Health Care

- Family Health

- Health Education

- Education, Continuing

- PET-Saúde

Recebido em: 01/04/2010

Reencaminhado em: 19/06/2010

Aprovado em: 04/07/2010

ReVISTA BRASILEIRA DE EDUCAÇ̄̃o MÉDICA
Tendo como princípios orientadores a integralidade e a humanização do cuidado, a Faculdade de Medicina de Botucatu (FMB) - Unesp busca reorientar a formação dos profissionais de saúde com o desenvolvimento de pesquisas e educação permanente na Estratégia de Saúde da Família. Este artigo analisa o primeiro ano do PET-Saúde desenvolvido na FMB e Secretaria Municipal de Saúde de Botucatu (SP). Foram selecionados como temas de investigação: saúde bucal de gestante, criança e idoso; imunização do adolescente; saúde do adulto e do idoso; e saúde e meio ambiente. Realizaram-se oficinas com a metodologia da problematização, produzindo-se modelos de intervenção nos quais alunos, docentes e profissionais de saúde dos serviços locais de saúde são protagonistas. O programa é um desdobramento da disciplina Interação Universidade, Serviço e Comunidade, ministrada de modo integrado aos cursos de Medicina e Enfermagem. Há resistências no interior da universidade, reconhecendo-se a desvalorização da prática clínica extra-hospitalar e na Atenção Básica. Nesse processo, o PET-Saúde vem fortalecer a prática acadêmica que interliga a universidade, em suas atividades de ensino, pesquisa, serviço e extensão, com demandas da sociedade, de forma partilhada.

\section{ABSTRACT}

Comprehensive and humanized care provides the underlying principles for the Botucatu School of Medicine (FMB/UNESP) in reorienting health professionals' training with the development of research and continuing education in the Family Health Strategy. This article analyzed the first year in the Educational Program for Health Work (PET-Saúde) developed by the School of Medicine and the Botucatu Municipal Health Department. The following research themes were selected: oral health in pregnant women, children, and the elderly; immunization in adolescents; health of adults and the elderly; and health and the environment. Workshops were held on the problem-solving methodology, producing intervention models in which students, faculty, and health professionals from local health services were the protagonists. The program is a spin-off of the course on Interaction between the University, Health Services, and the Community, given jointly to the courses in medicine and nursing. There is resistance inside the university, recognizing the devaluation of outpatient clinical practice and primary care. In this process, the PET-Saúde program is intended to strengthen academic practice that links the university with its teaching, research, services, and extension activities to demands from society, in a shared approach. 


\section{INTRODUÇÃO}

No Brasil, os ministérios da Educação e da Saúde vêm construindo de forma articulada, ao longo da última década, políticas públicas "para efetivar mudanças nos modelos de formação dos profissionais de saúde, tendo como princípios orientadores as Diretrizes Curriculares Nacionais e o Sistema Único de Saúde (SUS)"1 , respeitando "o exercício de suas prerrogativas constitucionais de regular, avaliar, supervisionar e ordenar a formação"1.

Tendo-se em conta a situação atual, em que vivenciamos um subfinanciamento do SUS, que se contrapõe ao desenvolvimento dos princípios da Reforma Sanitária em sua totalidade ${ }^{2}$, considera-se o Programa de Educação pelo Trabalho - Saúde (PET-Saúde) uma política pública desafiadora à consolidação do SUS. Isto ocorre por meio da valorização da atenção primária à saúde, especificamente na Estratégia de Saúde da Família (ESF); da formação permanente de todos os sujeitos envolvidos; da possibilidade de mudança na formação do profissional da área de saúde no nível universitário; e, principalmente, da implantação de projetos coletivos na ESF.

A FMB/Unesp é uma instituição de ensino superior (IES) pública, com $100 \%$ do seu ensino realizado no SUS, e integra o Programa Nacional de Reorientação da Formação Profissional em Saúde - Pró-Saúde I e II, em seus cursos de graduação em Medicina e Enfermagem, respectivamente, e a participação no programa PET-Saúde é uma oportunidade única para ampliar o compromisso de formação de profissionais de saúde na consolidação do SUS.

O desenho de trabalho do PET-Saúde oferece à nossa instituição a vivência de parceria com a Secretaria Municipal de Saúde de Botucatu (SP), particularmente no trabalho articulado com os profissionais do Programa de Saúde da Família, no qual se promovem estratégias de ensino-aprendizagem entre todos os envolvidos: tutores, preceptores e estudantes monitores bolsistas e estudantes não bolsistas, e no qual incluímos também os agentes comunitários de saúde, a residência médica e multiprofissional na ESF e a comunidade local.

Para desenvolver o programa, estruturou-se um grupo de trabalho com a participação de docentes, estudantes, membros da comissão Pró-Saúde, enfermeiros, residentes e profissionais da universidade e dos serviços que atuam na disciplina Interação Universidade Serviços e Comunidade (Iusc) e representantes do Núcleo de Excelência em Pesquisa Aplicada à Atenção Básica, criado em 2009 por Portaria do diretor da FMB, com o objetivo inicial de mapear as pesquisas realizadas e as que estão em andamento na Atenção Básica à Saúde no município de Botucatu, com possibilidade de maior visibilidade das referidas pesquisas.
Foram realizadas oficinas com a metodologia da problematização, produzindo-se modelos de intervenção em que todos são protagonistas e nos quais se observa maior aproximação da universidade com a ESF, proporcionando maior reflexão a professores e estudantes, que, confrontados com a realidade, aprendem e produzem conhecimentos. O profissional da ESF amplia sua "cultura de investigação" ao incorporar em seu fazer cotidiano a habilidade de identificar e buscar soluções para os problemas e dificuldades enfrentados, mediante reflexão e análise crítica de sua prática. A cultura da participação e do trabalho em equipe e a responsabilização dos equipamentos formadores com os prestadores de serviços e a comunidade são um processo que necessita de acompanhamento, reflexão e avaliação permanentes ${ }^{3}$.

O PET se realiza como um desdobramento de disciplinas, denominadas Interação Universidade, Serviço e Comunidade (Iusc), implantadas do primeiro ao terceiro ano de graduação de Medicina e do primeiro ao segundo ano de graduação em Enfermagem, com a participação de 330 estudantes, contextualizando-se a proposta em um projeto maior de mudança da educação médica e de Enfermagem.

A Iusc adota como estratégia de ensino-aprendizagem a vivência dos estudantes para além do ambiente cotidiano - a faculdade -, inserindo-os em territórios de UBS e USF da rede pública municipal de saúde de Botucatu, possibilitando que aprimorem o olhar, a escuta e o conhecimento sobre a cidade, o bairro, o território. Também se propõe a uma atenção à saúde na qual, no atendimento à população, os profissionais de saúde buscam conhecer como vivem as famílias e como estas solucionam os problemas de saúde, considerando questões culturais, cognitivas e subjetivas no funcionamento dos serviços de saúde ${ }^{4}$.

Desde sua configuração inicial, em 2003, a Iusc trabalha de forma interdisciplinar em sua organização curricular e por meio da problematização acerca da realidade na Atenção Básica, na comunidade e na sociedade contemporânea, suscitando questões para investigação, e proporcionando, assim, maior participação do estudante em seu processo de formação. Tem como base teórica os conceitos de integralidade e humanização do cuidado. A integralidade é compreendida como princípio jurídico-institucional do SUS, definida como um conjunto articulado de ações e serviços de saúde, preventivos e curativos, individuais e coletivos, nos diversos níveis de complexidade do sistema e com vista a "uma produção do cuidado eficaz, humanizada e, portanto, efetivamente centrada nas necessidades dos usuários individuais e coletivos dos serviços de saúde" ${ }^{\prime \prime}$. A humanização é aqui entendida no sentido de uma dimensão essencial do cuidado que busca "uma 
reorientação dos modos de cuidar e de promover a saúde, tendo em vista o processo de responsabilização e comunicação dialógica entre governantes, usuários, profissionais de saúde, formadores e alunos" ${ }^{\prime \prime}$. Considera a Constituição Federal de 1988 e a instituição do SUS como avanços essenciais ao desenvolvimento de políticas públicas de saúde no Brasil e que esses valiosos progressos em prol da melhoria da qualidade dos serviços ofertados à população precisam se articular e evoluir para uma necessária revisão na formação dos profissionais de saúde.

O PET-Saúde vem fortalecer uma prática acadêmica que objetiva interligar a universidade, em suas atividades de ensino, pesquisa, serviço e extensão, com demandas da sociedade, de forma extremamente construtiva.

A implantação desta prática não é fácil e encontra resistências no interior da IES, inclusive no que se refere à possibilidade de desenvolvimento de um ensino adequado na ESF, tendo em vista o descrédito na prática clínica extra-hospitalar e na Atenção Básica por parte de alguns docentes da instituição. A Atenção Básica ainda possui má reputação entre os médicos que atuam no nível hospitalar porque muitos desconhecem o trabalho lá realizado ou as ferramentas necessárias para lidar com a demanda ali presente.

Reconhecemos no trabalho PET que a ESF contém uma série de ações para além da intervenção curativa individual, que envolvem um trabalho complexo para se obter "alta capacidade resolutiva e ao mesmo tempo alta sensibilidade diagnóstica, para atuar corretamente nas demandas primárias e propor encaminhamento adequados no interior do sistema assistencial $^{\prime \prime 6}$. Tendo como base as questões aqui elencadas, relata-se a experiência do primeiro ano de concretização do PET-Saúde da FMB/Unesp, realizada em parceria com a Secretaria Municipal de Saúde de Botucatu.

\section{OBJETIVO}

Este artigo descreve, explora e analisa a experiência do primeiro ano de desenvolvimento do PET-Saúde da FMB/UNESP, realizada em parceria com a Secretaria Municipal de Saúde de Botucatu.

\section{PERCURSO METODOLÓGICO, CONSTRUÇÂO DO PET-SAÚDE DA FMB/UNESP E ORGANIZAÇÂO DO TRABALHO}

O PET-Saúde da FMB/Unesp, desenvolvido em parceria com a Secretaria Municipal de Saúde de Botucatu, tem como objeto de pesquisa de intervenção proporcionar ao estudante de graduação em Enfermagem e Medicina, aos professores da FMB e aos profissionais da ESF a vivência em ações e atividades de pesquisa na ESF como expedientes vitais ao processo de ensino-aprendizagem pela metodologia tutorial, vinculados à vivência do/no real como uma relação dialética entre teoria e prática, e possibilitar a construção do conhecimento na perspectiva do desenvolvimento e qualificação da ESF e, como consequência, a qualificação do serviço oferecido à população.

Assim, trata-se de um projeto de intervenção, na modalidade de pesquisa participante, de desenho exploratório, em que o principal objetivo do estudo é interferir na realidade para modificá-la. Seu compromisso é não só propor soluções para os problemas, como também resolvê-los efetivamente e de modo partilhado. Trata-se, na realidade, de um Projeto de Pesquisa e Desenvolvimento ${ }^{7}$, do qual tomam parte pessoas implicadas no problema pesquisado, assumindo que têm um papel no contexto a pesquisar. Nesse projeto, está claro o princípio pedagógico da indissociabilidade entre ensino, pesquisa e extensão, no contexto da ESF do município de Botucatu.

As atividades do grupo PET-Saúde se iniciaram em setembro de 2008, quando da organização da concepção do projeto, com reuniões e oficinas, e a formação de um grupo de trabalho com a participação de todos os segmentos envolvidos na redação do projeto.

O grupo de pesquisa PET-Saúde da FMB/Unesp de aprendizagem tutorial de natureza coletiva e interdisciplinar que desenvolveu o projeto vinculado à ESF foi composto por 5 tutores e 2 cotutores acadêmicos, 36 preceptores e 72 estudantes monitores. Esse grupo foi responsável pela aprendizagem em serviço de 120 estudantes do segundo ano de Medicina e Enfermagem, e de 90 estudantes de Medicina do terceiro ano, totalizando 210 estudantes. Realizaram atividades nos territórios das USF e UBS de Botucatu 120 estudantes do primeiro ano de Medicina e Enfermagem da disciplina Iusc, sob a tutoria de outros professores da FMB e profissionais da rede e da FMB.

O grupo PET-Saúde teve a coordenação geral dos trabalhos, que coincidiu com a coordenação do Pró-Saúde e que orientou todo o trabalho.

Os tutores, preceptores e estudantes bolsistas atuaram nas disciplinas da Iusc e na parceria com a Residência Multiprofissional em Saúde da Família e Comunidade, e realizaram em subgrupos a aprendizagem tutorial de natureza coletiva e interdisciplinar com o desenvolvimento dos projetos segundo o que foi levantado como prioridade entre os componentes e as demandas das USF. Os docentes tutores exerceram função de supervisão docente-assistencial, em campo, com o papel de orientadores dos projetos de pesquisa sob sua responsabilidade para os profissionais e estudantes bolsistas. 
O projeto foi desenvolvido em Botucatu, município com cerca de 120 mil habitantes, localizado na região centro-sul do Estado de São Paulo. O município é sede do Polo de Educação Permanente, com envolvimento e participação ampla da universidade (Polo Sudoeste Paulista de Educação Permanente).

$\mathrm{O}$ universo de pesquisa foi composto pelas unidades de saúde da família, seus respectivos territórios e comunidades, e pela rede de serviços SUS na qual se insere a ESF. Atualmente, há 16 unidades de Atenção Básica à Saúde: três policlínicas (PC); três Centros Municipais de Saúde (CMS) e duas unidades do Centro de Saúde Escola (CSE), que trabalham sob o modelo da Atenção Básica, e oito Unidades de Saúde da Família (USF), que abrigam 16 equipes mínimas completas e respectivas equipes de saúde bucal.

O Programa de Saúde da Família (PSF), hoje denominado ESF, foi implantado, em Botucatu, em 2003, mediante processo de reordenamento da rede de atenção à saude, em territórios considerados prioritários devido a diversos fatores, como precária condição socioeconômica, difícil acesso e demanda reprimida aos serviços de saúde. Algumas unidades da ESF implantaram-se em caráter substitutivo a antigas unidades básicas de saúde e outras foram construídas em novos territórios. Atualmente, cerca de $30 \%$ da população é coberta por USF. O PET se desenvolveu em todas as USF de Botucatu.

No desenvolvimento do projeto, utilizaram-se, como material para análise, documentos oficiais, questionários aplicados, relatórios de reuniões, anotações de acompanhamento dos estágios, textos produzidos nos serviços pelos estudantes, profissionais e professores. A pesquisa de campo foi realizada por meio de observação direta, indireta, participante, entrevistas e questionários, visitas domiciliares, processos de formação e desenvolvimento profissional.

A avaliação do processo ocorreu por meio de indicadores quantitativos e qualitativos elaborados para acompanhar o desenvolvimento dos trabalhos de cada grupo de pesquisa e o desenvolvimento das disciplinas e da educação permanente, com a participação dos principais responsáveis pela coordenação da ESF municipal e de todos os envolvidos. A avaliação proposta teve duplo papel: avaliar para qualificar o processo de pesquisa e de ensino na comunidade e propor intervenções para qualificar a ESF.

A pesquisa foi realizada nos termos das Portarias 196/96 e 251/97, do Conselho Nacional de Saúde e do Programa Iusc, e todos os grupos tiveram seus projetos aprovados pelo Comitê de Ética da Faculdade de Medicina da Unesp/Botucatu.

\section{RESULTADOS: O PET-SAÚDE DA FMB/UNESP COMO UM PROJETO EM PERMANENTE CONSTRUÇÃO}

\section{A amplitude do Trabalho dos Grupos PET-Saúde da FMB/ Unesp}

De forma geral, todos os objetivos e metas propostos estão se desenvolvendo, e a maior riqueza do programa é a diversidade dos projetos PET e a interação do desenvolvimento destes com a prática pedagógica realizada na Iusc e no ensino na ESF. Ao examinarmos cada um dos projetos, percebemos a amplitude de nosso programa ao constatarmos os objetivos e metas que se vêm alcançando. Os projetos têm ampla diversidade de objetivos e metas, como: conhecer a percepção de gestantes e mães sobre a saúde bucal e promover estratégias no cuidado da gestante e seu bebê; avaliar a situação vacinal dos alunos adolescentes, de 10 a 19 anos, do município de Botucatu, o que tem proporcionado a participação de estudantes em medidas de controle e avaliação da prática na ESF; identificar possíveis falhas nos programas de vacinação e propor soluções. Como exemplo do trabalho de avaliação de cobertura vacinal, identificou-se em um território que 39,25\% dos adolescentes não receberam a primeira dose da vacina contra hepatite $\mathrm{B}$.

No projeto que visa conhecer a percepção da saúde bucal de idosos atendidos em serviço de saúde na atenção primária, tem sido possível aproximar os acadêmicos dos idosos na Atenção Básica, realizar exames da cavidade bucal, diagnosticar a condição da saúde bucal pelos dentistas, levantar a condição de saúde bucal dos idosos atendidos, orientar sobre medidas preventivas e promocionais referentes à saúde bucal pelos acadêmicos e encaminhar para tratamento adequado. Na pesquisa que prioriza a atenção domiciliar ao idoso, tem sido possível avaliar e intervir nas situações de risco dos idosos e ampliar a visão do estudante sobre o cuidado ao idoso.

No projeto voltado a identificar a clientela portadora de hipertensão arterial assistida em Unidade de Saúde da Família (USF), foi possível verificar as condições de saúde de indivíduos portadores de hipertensão arterial relacionadas aos fatores de risco para esta doença; levantar as causas de abandono de tratamento, acompanhamento e participação nas atividades em grupo e individuais; detectar as facilidades e dificuldades para realizar o tratamento proposto; e buscar sugestões para ampliar e melhorar o atendimento da USF.

Na atenção ao diabético tipo 2, foi possível explorar as possibilidades de operacionalização de estratégias de educação e comunicação voltadas para apoiar o autocuidado do paciente e compreender melhor a percepção do paciente diabético. 


\section{A FORMAÇÃO PERMANENTE DO PROFESSOR E PRECEPTOR DA ESF}

Uma das ações priorizadas no PET-Saúde da FMB é a implementação de atividades de formação permanente dos professores e preceptores do programa e na qual se pode perceber um rico processo de desenvolvimento profissional. Esse trabalho tem como objetivos: (a) ampliar a reflexão/ação para o processo de ensino-aprendizagem na Atenção Primária à Saúde; (b) refletir sobre a integração de ações e atividades do ensino-aprendizagem na Atenção Primária à Saúde com as demandas e necessidades da rede; (c) instrumentalizar professores para o trabalho de preceptoria na rede com a utilização da metodologia da problematização nos trabalhos com os grupos de alunos; (d) promover a reflexão e a qualificação do processo de trabalho na ESF e na articulação da rede como um todo.

Em julho de 2009, todos os bolsistas preencheram relatório individual parcial sobre sua participação nos trabalhos dos Grupos PET-Saúde. Em outubro de 2009, todos os preceptores realizaram uma primeira avaliação escrita dos trabalhos realizados e uma reflexão sobre sua participação no processo e o impacto do programa PET-Saúde. Uma primeira análise desse material permite constatar responsabilidade, envolvimento e disposição de todos na construção dessa parceria e no desenvolvimento desse trabalho de ensino superior na ESF com a realização de pesquisa de intervenção e ensino na Atenção Básica. Observa-se que $100 \%$ dos preceptores têm interesse em dar continuidade ao trabalho desenvolvido em 2010 e todos consideram a oportunidade de atuar no PET como uma chance de desenvolvimento profissional.

Sobre a formação dos preceptores, Nóvoa ${ }^{8}$ observa que devemos valorizar e implementar um processo no qual os preceptores aprendam a partir da análise e interpretação da sua própria atividade, ou seja, "a profissão de professor conduz à criação de um conhecimento específico adquirido através da prática". Tem sido possível trabalhar a educação permanente dos preceptores envolvendo o exame constante das próprias experiências, o diálogo crítico com teorias "e o reconhecimento de que a postura reflexiva deve marcar o trabalho docente". Esse processo tem favorecido a construção da autonomia para identificar e superar as dificuldades do cotidiano?.

Neste ano descobri como é complexo o gerenciamento entre alunos e unidade de saúde. Há interesses convergentes e divergentes. O trabalho do preceptor passa pela mediação $e$ construção de espaços de diálogo entre os envolvidos, o que não é uma tarefa fácil. Aos poucos percebi que o trabalho pode ser enriquecedor para todos: alunos e trabalhadores. (preceptor ESF, $2^{\circ}$ ano, Enfermagem e Medicina)
Como questiona Balzan ${ }^{10}$ : é possível trabalhar, no ensino médico e de Enfermagem, "situações de ensino e aprendizagem em que professores e alunos trabalhem em conjunto na busca de soluções para problemas extraídos da realidade homem, saúde e sociedade?" Esse tem sido o desafio dessa proposta de formação.

A inserção dos alunos no contexto das unidades de Saúde da Família faz com que se tornem profissionais com um olhar diferenciado para o contexto de vida dos clientes assistidos por esses profissionais. Serão profissionais capazes de desenvolver o trabalho em equipe multiprofissional respeitando as diversas categorias envolvidas na assistência, já que em suas atividades programadas estão em articulação o tempo todo com diversos profissionais. Outra coisa importante é a contribuição da pesquisa desenvolvida, pois existe um levantamento do diagnóstico em saúde das áreas que estão atuando para discussão de possíveis intervenções para aquela população. (preceptor pesquisador da ESF)

A formação permanente ocorre de forma regular para todos os preceptores de cada ano. São encontros semanais de quatro horas, de fevereiro a dezembro, com grupos de cerca de 12 professores cada, totalizando 120 horas de formação para cada grupo/ano.

Considero a atividade uma forma de aprendizado e atualização da parte do profissional da rede básica, pois de certa forma nos incentiva a estudar mais para poder sanar possíveis dúvidas dos alunos, além de também nos estimular a estar sempre nos reciclando para muitos temas pelos quais possivelmente não nos interessaríamos mais. Resumindo, o impacto é extremamente positivo. (preceptor ESF, 3 on ano, Medicina)

Considerando a natureza complexa da realidade e buscando evitar reducionismos e simplificações, trabalha-se sempre procurando enfatizar o relato da vivência da prática profissional de cada um. Os preceptores têm formações distintas (dentistas, enfermeiros, pedagogos, médicos, psicólogos, fonoaudiólogos, assistentes sociais, fisioterapeutas, sociólogos), contribuindo com diferentes olhares e significados do trabalho em equipe. Assim relata uma dentista preceptora de estudantes de Medicina e Enfermagem sobre seu trabalho no PET-Saúde:

O maior impacto para o meu trabalho profissional foi a minha contribuição para a formação dos profissionais de saúde e a minha participação no desenvolvimento de pesquisa científica, o que despertou em mim o interesse por continuar me aperfeiçoando e pela área acadêmica. (preceptora pesquisadora da ESF) 
Assim, busca-se instituir relações orgânicas entre todos na prática de formação, produção de conhecimento e cooperação acadêmica.

Eu avalio o meu envolvimento com o PET como enriquecedor do ponto de vista acadêmico e de conhecimento, uma vez que me trouxe novamente a oportunidade de atuar no desenvolvimento de uma pesquisa científica. Além disso, amplia meus conhecimentos numa área da saúde que não estudei tão especificamente na graduação, mas que é essencial na minha atuação clínica diária (hipertensão arterial). (preceptora pesquisadora da ESF)

Considera-se que o PET-Saúde, uma parceria da FMB/ Unesp com a Secretaria de Saúde de Botucatu, tem fomentado grupos de aprendizagem tutorial na Estratégia Saúde da Família (ESF) articulando o ensino na comunidade com os serviços de saúde e atividades de pesquisa e extensão na atenção primária à saúde.

Achei estimulante trabalhar com alunos do terceiro ano da graduação em Medicina que estão iniciando sua prática clínica supervisionada e poder contribuir na formação dos mesmos, discutindo a clínica ampliada que possibilita a eles desenvolverem vínculo com pacientes de uma área adscrita, valorizando as características da comunidade, sua cultura, relações sociais, de trabalho e com o serviço de saúde. (preceptora, 3o ano, Medicina)

\section{PARCERIAS ESTABELECIDAS E ARTICULAÇÃO ENTRE A FMB E A GESTÃO MUNICIPAL DE SAÚDE}

O projeto se desenvolveu em todas as Unidades de Saúde da Família do município, com preceptores de todas as unidades de Botucatu. Sua construção contou com a participação dos profissionais que atuam na ESF, buscando-se contemplar a interdisciplinaridade e responder a possibilidade de produção de conhecimento a partir das demandas e propostas de pesquisas trazidas pelos profissionais da ESF no campo da integralidade do cuidado.

Meu envolvimento com o PET foi ótimo em minha opinião, nossa tutora excelente, os alunos dedicados à pesquisa. Gostaria de poder dar continuidade ao nosso trabalho porque foi uma nova experiência que me proporcionou uma visão ampla em pesquisa para melhorar meus conhecimentos e o atendimento na unidade. (preceptora pesquisadora da ESF)

Em todos os projetos, a parceria entre a universidade, o Serviço de Saúde Municipal e a comunidade foi contemplada. Alguns projetos surgiram de demandas do serviço, como no caso da saúde bucal do idoso, que tem como preceptores cirur- giões-dentistas da Estratégia Saúde da Família numa região do município com 9 mil usuários cadastrados, dos quais 705 são pacientes idosos. Outro projeto, voltado a ações no meio ambiente, estabeleceu parcerias com instâncias municipais, como o serviço de vigilância em saúde ambiental (para conhecer o trabalho e levantar os riscos ambientais de dois territórios) e a Escola do Meio Ambiente (para a realização de atividades com os profissionais neste cenário e acompanhamento dos monitores). Esse projeto também envolveu a Cooperativa de Catadores de Lixo, para desenvolver oficinas de orientação aos catadores de lixo, frente ao grande volume de material recolhido pela população e armazenado erroneamente.

\section{O TRABALHO DE APOIO DO AGENTE COMUNITÁRIO DE SAÚDE AO PET E O APOIO AO AGENTE COMUNITÁRIO DE SAÚDE}

O desenvolvimento dos grupos PET e de todo o ensino na ESF tem sido engrandecido com a participação do agente comunitário de saúde (ACS) de cada uma das equipes. O ACS atua como o sujeito que permite a ligação entre profissionais, o grupo PET e a comunidade. Como o ACS está em contato permanente com as famílias, mora no território e conhece a população, facilita o trabalho realizado pela equipe. É também um elo cultural, que possibilita maior desenvolvimento do trabalho educativo ao juntar dois universos culturais: o do saber científico e o do saber popular. Todo o trabalho realizado nos domicílios de cada área de abrangência tem tido a participação e apoio do ACS. Também tem sido possível, por meio de seu trabalho e conhecimento sobre a situação das famílias acompanhadas, a percepção de situações de risco e de necessidade de apoio e intervenção. Na fala de uma preceptora pesquisadora e de um preceptor professor:

\begin{abstract}
A aproximação dos ACS no ensino da graduação contribui para a formação do profissional da saúde com uma visão integral do processo saúde-doença. O ACS apresenta ao estudante o meio em que está inserido o paciente, através das visitas domiciliares, e quais as situações de risco da comunidade, o que auxilia no processo de aprendizagem dos acadêmicos com base na problematização da realidade. Além disso, contribui para a formação acadêmica multiprofissional, contextualizada e resolutiva, garantindo a atenção à saúde individual e coletiva, pautada nos princípios do SUS. (preceptora pesquisadora)
\end{abstract}

Para os estudantes, os ACS colaboram no desenvolvimento de ações de educação e vigilância à saúde, com ênfase na promoção da saúde e na prevenção de doenças, e ainda traduzem a dinâmica social da comunidade, suas necessidades, 
potencialidades e limites, e a identificação de parceiros e recursos existentes na comunidade que possam potencializar as ações e atividades dos grupos.

O trabalho do ACS, na graduação dos dois cursos, fornece informações importantes relativas à comunidade na qual trabalham, como a real condição socioeconômica da população e não dados teóricos da mesma. Mostrando essa real condição, os alunos aprendem na prática como devem se portar frente ao futuro paciente que atenderão, o vocabulário a ser utilizado e qual estratégia utilizar para melhor aderência ao tratamento. O dia a dia dos ACS mostra claramente para os alunos essa realidade e o quanto é enriquecedor esse conhecimento. (preceptor, 3a ano médico)

A partir da percepção da necessidade dos agentes comunitários de saúde de ter um espaço de fala e escuta diante de suas angústias, tendo em vista seu papel na comunidade, foram realizados, de outubro de 2009 a março de 2010, encontros periódicos, com base na Terapia Comunitária, com mediação de uma médica. Os agentes compuseram um grupo de bolsistas, com apoio do Pró-Saúde I, com a formação de grupos de ACS de todas as Unidades de Saúde da Família (USF) de Botucatu. Cada grupo de agentes tomou parte de cinco a seis encontros, sendo que cada grupo contou com 12 a 18 participantes. As reuniões foram organizadas como um espaço de vivência e trocas, com relatos de experiências do cotidiano do trabalho na comunidade. Por se tratar de um grupo de profissionais extremamente identificados com a comunidade, os problemas de ordem pessoal muitas vezes se mesclaram ou permearam o relato do trabalho profissional. Isto possibilitou a abertura de um processo de reflexão sobre identidade pessoal e profissional, apoiando e fortalecendo o compromisso com o trabalho desenvolvido nas USF. Nas palavras da mediadora:

Reconheço nesse trabalho uma ampliação do meu encontro com a comunidade que, na pessoa dos agentes, me aproximou de questões, percepções e sábias estratégias de enfrentamento dos individuos nas suas histórias de vida. Cada momento de troca e narrativa me proporcionou aprendizado e renovado desejo de trabalho no espaço grupal.

\section{CONSIDERAÇÕES FINAIS: IMPACTOS, DIFICULDADES, ESTRATÉGIAS DE ENFRENTAMENTO E SUSTENTABILIDADE}

Sistematizar, a partir do relato e da análise, e socializar a vivência desse primeiro ano de PET foi tão produtor de conhecimento e de apropriação de um saber/fazer quanto com- preender a riqueza da continuidade do desenvolvimento do processo.

Acreditamos o que o maior impacto do programa PET-Saúde da FMB foi a possibilidade de desenvolvimento do trabalho de ensino e pesquisa de intervenção construído e executado conjuntamente, fortalecendo a parceria entre as USF e a universidade. Além do convívio com os alunos, os profissionais da ESF se sentiram valorizados pela oportunidade de mostrar aos estudantes como é o trabalho médico e dos outros profissionais fora da Academia, inserido numa equipe de saúde e junto a uma população bem conhecida, e também se perceberam ampliando a rede de contatos com profissionais envolvidos com o programa nas USF.

O fato de ser um bolsista PET-Saúde e se sentir parte do programa foi extremamente gratificante para todos. Esse movimento em construção foi percebido como muito engrandecedor para todos os envolvidos, incluindo-se aqui, além dos bolsistas, a comunidade acadêmica, as equipes da ESF e a comunidade atendida.

\section{O maior benefício/impacto do PET-Saúde é o aspecto moti- vacional e inovador dentro do ambiente de trabalho. Como coordenadora de unidade de ESF, um dos elementos mais di- fíceis para desenvolver com a equipe é a motivação da mesma. Propor novos desafios e trabalhar com técnicas inovadoras para produzir um trabalho mais eficaz têm deparado quase sempre com resistência por parte dos colaboradores. O PET- -Saúde tem se mostrado bastante efetivo neste aspecto, pois os alunos não colocam barreiras ou impedimentos para novas ações. Com isso, eles colaboram para implantar uma filosofia de inovação e constante aperfeiçoamento. (preceptora, $1^{\circ}$ ano, Enfermagem e Medicina)}

Um benefício percebido e muito valorizado se refere à possibilidade de formação e ao estímulo ao estudo, à atualização, à transformação. Durante as pesquisas, os profissionais observaram o quanto podem melhor seu trabalho no atendimento ao usuário e também envolver a equipe.

\footnotetext{
Com os resultados parciais da pesquisa que realizamos, pudemos observar o campo extenso que temos ainda para pesquisar e para realizar atividades preventivas e educativas para a comunidade e, ainda, a importância do trabalho realizado junto com os alunos, onde ocorreram trocas de experiência e aprendizado sobre outras áreas da saúde. (preceptor pesquisador)
}

A maior aproximação entre a universidade e a população, sendo os alunos parceiros da equipe na promoção da saúde, 
foi considerada como um apoio à ampliação do conhecimento de demandas das áreas que necessitam de maior atenção, e que algumas vezes permanecem esquecidas, e uma possibilidade de trazer novas ideias de estratégias para trabalhar com a população dessas áreas.

Outro impacto para as equipes da ESF se refere à possibilidade de, mediante o trabalho realizado durante este ano, estabelecer protocolos para melhorar a qualidade no atendimento da população no município e criar material didático específico padronizado.

O maior benefício foi a necessidade de atualização e revisão das técnicas de semiologia, bem como da clinica, para discussão dos casos com os alunos. Esse conhecimento também contribui para melhor atuação no atendimento dos pacientes fora do horário disponível para os alunos. (preceptor, $3^{\circ}$ ano, Medicina)

Uma questão também muito valorizada e tida como um impacto é a percepção da necessidade de buscar, por parte de todos, uma nova forma de aprender a ouvir, seguir e buscar compreender o pensamento e a ação do outro.

Na problematização da realidade e no processo de abstração vinculado à totalidade, trabalhou-se uma sequência de atividades didáticas, em que o aluno realizou operações de desenvolvimento intelectual, desde a descrição de dados da realidade, a comparação, a discriminação e a relação entre fatos na tentativa de explicá-los e assim poder avançar na compreensão de determinações mais amplas, até o exercício de planejamento de ações concretas ${ }^{11,12}$.

Assim, por exemplo, visitar regularmente as famílias pode significar a vivência dos estudantes de Enfermagem e Medicina como profissionais em formação, que se abrem para a possibilidade de troca, de acompanhamento, de convívio desde o início de sua formação, criando-se novas práticas que podem "mexer" com as pessoas e as relações entre elas.

Retornar à casa das famílias, muitas vezes reconhecido pelo estudante como algo que o incomoda, traz à tona questões pouco trabalhadas no curso médico:

A primeira refere-se à percepção de que ele, estudante, tem concepções distintas sobre muitos dados, informações e conversas trocadas com as famílias e esse fato pode lhe trazer um mal-estar, no sentido de se perceber com um saber que não é o único verdadeiro. $\mathrm{O}$ segundo incômodo pode se dar no retorno às casas quando o estudante percebe que deu uma orientação que entendeu como pertinente, sentiu-se com o dever cumprido ao passar a informação e frustra-se ao perceber que suas orientações não foram seguidas. Um terceiro aspecto complexo refere-se ao estudante perceber que voltando muitas vezes às casas fará vínculo e essa sensação pode lhe ser cara, no sentido de ter que se colocar em uma relação mais próxima, humanizada, comprometida, distante da postura academicista e alienante vivenciada no hospital-escola, no qual os pacientes estão ali, todos, sem importar sua origem, cultura ou vida e onde o que se valoriza é a doença e não o doente ${ }^{13}$.

Outro ponto de impacto do programa, considerado condição básica para a humanização do cuidado, foi a valorização do trabalho em grupo, no qual tutores, preceptores e estudantes atuam de forma cooperativa, "conformando uma ética solidária no trabalho, fato relevante para a qualidade existencial"'6.

A valorização do reconhecimento do território para além da superfície geográfica como atividade necessária e inerente ao processo de trabalho em saúde, o comprometimento com a realidade de cada comunidade tem possibilitado a percepção de que existem homogeneidades e heterogeneidades entre os diferentes grupos populacionais.

Como nos aponta Nascimento ${ }^{14}$ :

\begin{abstract}
A marca indelével de um trabalho desse tipo é o caráter coletivo do seu processo [...]. Ele não será nunca coisa acabada. Ele é agora um caleidoscópio de mil faces, lados, peças, imagens, ideias, críticas, palavras, ações e sentimentos transformadores e integradores, em novas formas e dimensões, que também serão percebidos e vividos de maneiras diversas.
\end{abstract}

Quanto às dificuldades encontradas, a maior delas, por todos apontada, se refere à impossibilidade de maior tempo de dedicação às pesquisas por parte de todos. Os estudantes se sentem divididos entre estar mais na comunidade e ter que dar conta de um currículo tão pesado e com tantas disciplinas. Muitos grupos acabaram por trabalhar nos finais de semana e mesmo no período noturno para dar conta desse problema. Também para os preceptores o quesito tempo foi considerado uma dificuldade para maior envolvimento, dada a escassez de profissionais em algumas equipes da ESF e a enorme quantidade de trabalho.

Outra fragilidade observada se relaciona a dificuldades próprias do funcionamento da rede básica municipal, que, muitas vezes, não tem condições de oferecer espaço físico adequado e suficiente para a presença dos alunos nas USF. Com 
freqüência, os estudantes se sentem incomodados por atrapalharem a rotina nas USF, trazendo mais demandas ao serviço ou ocupando o espaço físico.

Outra dificuldade diz respeito à percepção dos participantes da necessidade de organização dos outros níveis de assistência no município, notando-se, especificamente, a ausência de uma rede regionalizada de referência e contrarreferência de serviços assistenciais:

\begin{abstract}
Assim, percebem-se os limites do trabalho na APS, que, por si só, mesmo realizando um trabalho de qualidade sob uma ótica ampliada do cuidado, não altera substantivamente a lógica organizativa dos serviços, em que predomina a assistência a doenças em suas demandas espontâneas, centradas no apoio diagnóstico, equipamentos e medicamentos ${ }^{15}$.
\end{abstract}

Apesar da falta de governabilidade do PET para lidar com a resolução dos problemas apontados, todas as dificuldades encontradas foram analisadas e encaminhadas.

Colocar em prática os princípios da Educação Permanente no desenvolvimento do PET propiciou atuar em um universo dinâmico, composto por uma complexa diversidade de saberes e modos de saber/fazer instituídos, "produzindo questionamentos onde caberiam apenas certezas"16 na tentativa de criar, recriar e potencializar "novos modos de fazer saúde"16 e possibilitar uma nova convivência em espaços coletivos onde conflitos existentes e, muitas vezes, cristalizados entre IES e serviços possam emergir como um espaço de construção e formação a partir da reflexão e análise "das práticas, capaz de ressignificá-las e reconstruí-las"16.

\section{AGRADECIMENTOS}

Agradecemos à Diretoria da Faculdade de Medicina de Botucatu o apoio recebido, bem como aos professores e profissionais do Núcleo de Apoio Pedagógico da FMB por acreditarem no projeto.

Apoio: Este trabalho foi desenvolvido com apoio financeiro do Pró-Saúde I e II da FMB/Unesp e com apoio do programa PET-Saúde FMB/Unesp.

\section{REFERENCIAS}

1. Campos H. O desafio de formar o médico contemporâneo. Jornal O Povo, 2009 Out 18; Cad. Ciência e Saúde.

2. Sá MC. Em busca de uma porta de saída: os destinos da solidariedade, da cooperação e do cuidado com a vida na porta de entrada de um hospital de emergência. São Paulo;
2005. Tese [Doutorado] - Instituto de Psicologia da Universidade de São Paulo.

3. Prearo AY, Cyrino EG, Romanholi RMZ, Cyrino APP, Popim RC, Vilas Boas PJF et al. O processo de construção do PET-Saúde de Botucatu: desafios para universidade e serviços na formação de profissionais para o SUS. Anais do $47^{\circ}$ Congresso Brasileiro de Educação Médica; 2009 out. 17-20; Curitiba, PR, Brasil. Curitiba; 2009.

4. Vasconcelos EM. Educação popular e a atenção à Saúde da Família. São Paulo: Hucitec, Ministério da Saúde; 1999.

5. Silva JPV, Tavares CMM. Integralidade: dispositivo para a formação crítica de profissionais de saúde. Rev Trabalho Educ Saúde. 2004;2:271-85.

6. Schraiber LB, Mendes Gonçalves, RB. Necessidades de saúde e atenção primária. In: Schraiber LB, Nemes MGRB, org. Saúde do adulto: programas e ações na unidade básica. São Paulo: Hucitec; 1996. p.29-47.

7. Tobar RF, Yaloru MR. Como fazer teses em Saúde Pública. Rio de Janeiro: Fiocruz; 2001.

8. Nóvoa A. Os professores e sua formação. Lisboa: Publicações Dom Quixote; 1995.

9. Zeichner KMA. A formação reflexiva de professores: idéias e práticas. Lisboa: Educa; 1993.

10. Balzan NC. Formação de professores para o ensino superior: desafios e experiências. In: Bicudo MA, org. Formação do educador e avaliação educacional. São Paulo: Ed. Unesp; 1999. v.2.

11. Saviani D. Escola e democracia. 33ae ed. Campinas: Editores Associados; 2001.

12. Vasconcellos CS. Construção do conhecimento em sala de aula. 12 $2^{\underline{a}}$ ed. São Paulo: Libertad; 2001. (Cadernos Pedagógicos do Libertad, 2).

13. Cyrino EG, Martins STF, Prearo AY, Manoel CM, Oikawa LT, Vecchia MD et al. Em busca da recomposição da arte do cuidado e do fazer / aprender: a interação universidade, serviço, comunidade na FMB/UNESP. In: Pinheiro R, Ceccim RB, Mattos RA, org. Ensino-trabalho-cidadania. Rio de Janeiro: Abrasco; 2006. p.71-84.

14. Nascimento E, Rezende AL. Criando historias aprendendo saúde. São Paulo: Cortez; 1988.

15. Gonçalves RJ, Soares R, Troll T, Cyrino EG. Ser médico no PSF: formação acadêmica, perspectivas e trabalho cotidiano. Rev Bras Educ Méd. 2009;33(3):393-403.

16. Lauer PC. A educação permanente enquanto estratégia de fortalecimento de ações de saúde mental na atenção básica. São Paulo; 2010. Monografia [Graduação] - Faculdade de Ciências Médicas da Santa Casa de São Paulo. 


\section{CONTRIBUIÇÃO DOS AUTORES}

Eliana Goldfarb Cyrino idealizou o projeto como um todo e participou da revisão da literatura e na interpretação dos resultados, assim como da elaboração, discussão e redação do relatório final do projeto e deste artigo. Antonio de Pádua Pithon Cyrino, Alice Yamashita Prearo e Paulo José Fortes Villas Boas elaboraram e desenvolveram os subprojetos de cada tema estudado, participaram na elaboração e correção do relatório final do projeto, assim como da revisão da literatura e no processo de redação e discussão do artigo. Regina Célia Popim, Janete Pessuto Simonetti, Miriam Hashimoto e Karina Pavão Patrício elaboraram e desenvolveram os subprojetos de cada tema estudado, participaram na elaboração e correção do relatório final do projeto e na redação deste artigo. Renata Maria Zanardo Romanholi, Cássia Marisa Manoel e Paula de Oliveira Montandon Hokama participaram na elaboração, discussão e correção final do relatório do projeto e na redação deste artigo.

\section{CONFLITO DE INTERESSES}

Declarou não haver.

\section{ENDEREÇO PARA CORRESPONDÊNCIA}

Eliana Goldfarb Cyrino

Departamento de Saúde Pública da Faculdade de Medicina de Botucatu - Unesp

Distrito de Rubião Junior, s/no

Botucatu - São Paulo

CEP. 18618-970 SP

E-mail: ecyrino@fmb.unesp.br 